\title{
UNRAVELING DETERMINANTS OF WEBROOMING BEHAVIOR: A QUALITATIVE INQUIRY
}

\author{
Eugene Cheng-Xi Aw \\ School of Business and Economics, Universiti Putra Malaysia \\ UCSI Graduate Business School, UCSI University \\ Norazlyn Kamal Basha* \\ School of Business and Economics, Universiti Putra Malaysia \\ Siew-Imm Ng \\ School of Business and Economics, Universiti Putra Malaysia \\ Jo-Ann Ho \\ School of Business and Economics, Universiti Putra Malaysia
}

\begin{abstract}
Webrooming, a practice whereby consumers research for products online prior to making their final purchase offline, represents a prevalent form of shopping behavior in the current retailing landscape. This study aims to explore the determinants for and against the adoption of webrooming behavior among Millennials. Semistructured in-depth interviews were employed to collect data. Data were analyzed through theoretical thematic analysis. Results unveil a number of important themes, categorized based on consumers- (i.e., need for touch, need for interaction, price-comparison orientation, and product knowledge), channel-related factors (i.e., online search convenience, perceived usefulness of online reviews, perceived helpfulness of in-store salespeople, immediate possession, perceived risk), situational factor (i.e., product category), as well as experiential outcome (smart-shopping perception) that arose from webrooming. Considering the limited research on webrooming, this study advances the theoretical understanding on the determinants of webrooming, and offers managerial insight for retailers to deal with this popular shopping phenomenon.
\end{abstract}

Keywords: Webrooming, Cross-channel shopping behavior, Consumer traits, Shopping channel, Smartshopping perception, Product category

Received: 28 October 2020

Accepted: 27 September 2021

https://doi.org/10.33736/ijbs.4321.2021

\section{INTRODUCTION}

Due to the ever-changing retail landscape, consumer shopping behavior has shifted from the use of single channels, to the use of multichannels. Consumers these days combine the use of different shopping channels to take advantage of channel specific attributes in their shopping process as a means to acquire a better shopping experience (Papagiannidis et al., 2017; Santos \& Goncalves

*Corresponding author: Norazlyn Kamal Basha, School of Business \& Economics, Universiti Putra Malaysia, 43400 Serdang, Selangor, Malaysia; Email: norazlyn@upm.edu.my 
2019; Verhoef et al., 2015). Therefore, it is common for consumers to rely on a particular shopping channel for the purpose of information search, only to use an alternative shopping channel to complete the actual purchase (Viejo-Fernández et al., 2019). As the current retail environment is proliferated with different shopping channels, retailers have less control over the consumer purchase journey, leading to many different kinds of channel hopping or cross-channel behaviors (Lee \& Jung 2019). Literature suggests two dominant cross-channel shopping behaviors, which are; (1) showrooming, whereby consumers gather product information in physical stores and complete the purchase online, and (2) webrooming, whereby consumers research for product information online and make their actual purchase in physical stores (Flavián et al., 2016).

In the current competitive multichannel retail environment, it is crucial for retailers to have a better understanding on the drivers of cross-channel behaviours, in order to retain customers throughout the entire shopping process, and to better serve the market (Mosquera et al., 2019). To date, most studies on cross-channel shopping has focused on understanding showrooming behavior (Arora \& Sahney 2018a; Daunt \& Harris 2017; Gensler et al., 2017; Rapp et al., 2015), and much of this has to do with the gloom and doom hearsay on the threat of electronic commerce to brick-and-mortar stores. Lately however, there has been a host of literature that argues that physical stores remain the preferred channel for consumer purchases (Kim et al., 2019), and that $90 \%$ of all retail sales are captured in physical stores, resulting in monetary losses for pure online retailers. Webrooming, the most extended and popular cross-channel behaviour can possibly account for this undesired online retail sales performance (Aw, 2019). Based on a report by PricewaterhouseCoopers (2015), 70 percent of consumers intentionally engage in webrooming behaviour.

Indeed, the threat of webrooming behavior is evident in pure play online retailers. Not only does it cause loss of revenues, it also poses a huge burden on them to provide product information and a slew of online sales support, without a successful customer conversion rate (Heitz-Spahn, 2013). Webrooming results in reduced control of consumer experience by retailers, but more importantly, it poses the threat of free-riding behaviors (Flavián et al., 2019; Van Baal \& Dach, 2005). To explain, free-riding describes a situation in which consumers switch retailers during the course of cross-channel switching behavior, which eventually leads to the loss of sales for retailers. This means that even a multichannel retailer is at risk of losing out on sales, if they are unable to retain consumers within their channels throughout the entire stage of consumers' decision-making process. Therefore, to effectively manage webrooming behavior, retailers need to find an imminent answer to the drivers of webrooming behavior (Manss et al., 2020). Despite these reasonings, webrooming, as a most extended shopping behavior has been receiving relatively scant attention, as evidenced by the lack of literature on the phenomena (Flavián et al., 2016; Kleinlercher et al., 2020).

In the realm of multichannel retailing, the focal research question has evolved from, "why do people shop", to "why do people shop in the way that they do" (Harris et al., 2018). Correspondingly, the present study seeks to identify the important factors that drive consumers to engage in webrooming behavior, the experiences that consumers undergo throughout the webrooming process, and the conditions in which these phenomena is likely to occur. Past studies on online commerce have evidenced the motivations behind consumers online shopping behaviors, but have neglected the unique switching element behind that of webrooming. Due to the incomprehensive understanding of consumer webrooming behavior and the intention to avoid excessive preconceptions, the present study seeks to approach the proposed research questions: (i) 
what are the determinants of consumers' webrooming intention? and (ii) how consumers feel and think about webrooming? from a qualitative (theory-building) perspective. In particular, Millennials were chosen as the target generation in this study as they are highly involved in webrooming, and constitute a significant group of webroomers (Jain \& Shankar, 2021; Koetsier, 2018). It has been shown that webrooming is prevalent among 65\% of Millennial shoppers (Luthi, 2014). Notably, a later survey conducted by ORC International revealed that $95 \%$ of Millennial internet users followed a search online-purchase offline shopping journey in a past shopping season (McCarthy, 2017). Interestingly, it would be fruitful to understand why Millennials, who are generally considered digitally savvy and familiar with online shopping would end up making final purchase at physical stores (Aw et al., 2021). In addition, Millennials have high discretionary income, and thus represent a lucrative and strategically important market segment (Jain \& Shankar, 2021; Zollo et al., 2020).

The present study contributes to the existing body of knowledge on two counts. Firstly, this study is one of the pioneering researches to investigate webrooming phenomenon using a qualitative approach. By doing so, this study managed to uncover a wide array of factors leading to webrooming behavior, adding knowledge to an important niche area of multichannel retailing, echoing the call for action by Haridasan and Fernando (2018). More specifically, the present study finds a research model in few of the prior studies (Arora \& Sahney, 2018b; 2019; Aw 2019; Santos \& Goncalves, 2019) relevant but not sufficiently comprehensive in explaining webrooming. Several new consumer-, and channel-related factors have been identified, such as need for interaction, product knowledge, and perceived helpfulness of in-store salespeople. Coupling all the themes identified, the present study reinforces the idea that the conduct of webrooming is a result from both individual differences, and perceptions towards both online and offline shopping channels. Hence, the study provides a nice complement to prior webrooming research which centered on channel perception. Furthermore, the study unraveled consumer smart shopping experience, an involvement derived from the webrooming shopping process as an interesting outcome of webrooming behavior. In sum, the present study develops a preliminary theoretical ground, beyond the theory of planned behavior and technology acceptance model (Arora \& Sahney, 2019) for the webrooming phenomenon, suggesting that webrooming is motivated by a combination of individual traits, channel perception (benefits and costs), product categories, and shopping experience (smart shopping perception).

\section{LITERATURE REVIEW}

In the initial phase of multi-channel development, there were contention that a newly added channel could possibly replace or compete with the old ones; yet the popularity of channel combination by consumers have proven otherwise. As a matter of fact, channels should be treated as complementary in nature. The exhibition of cross-channel shopping behavior is primarily to help consumers to minimize discrepancies between channels (Boardman \& McCormick, 2018). To clarify, consumers find that different channels offer additional values, and are thus driven to approach a particular channel for what it excels at (Kalyanam \& Tsay, 2013). Hence, as a form of cross-channel consumption, webrooming represents one of the most popular forms of shopping behavior in the current retail landscape, yet only few studies have investigated this emerging phenomenon. 
The existing literature had been typically grounded based on an economic perspective in analyzing consumers' webrooming behavior. It has been articulated that consumers evaluate the costs and benefits of a channel use during the search and purchase phases of shopping process. Early research done by Verhoef et al. (2007) demonstrated that research shopping is compelled by attribute-based decision making, lack of lock-in, and cross-channel synergy. However, it has been claimed that their indirect way of modelling cannot be extended to webrooming behavior (Gensler et al., 2017; Santos \& Goncalves, 2019).

Later, Arora and Sahney (2019) empirically shown that online search benefits (i.e. online search convenience and accessing of online review) and offline purchase benefits (socialization, touch and feel, and sales-staff assistance) determine the attitude towards webrooming. In addition, Manss et al. (2020) revealed satisfactory aftersales service, channel-related price, and quality provided by online retailers reduce consumers' likelihood to engage in webrooming. Another stream of studies approach webrooming through the perspective of motivation. For example, Wolny and Charoensuksai (2014) used a personal diary-interview combination approach to investigate multichannel behavior. The study provided evidence that reference groups, such as influencers and friends can initiate webrooming behavior by triggering purchase needs, which in turn leads to extended information search and channel switching before arriving at a final purchasing decision. Likewise, several studies found that information-processing and uncertainty-reduction motivation compels consumers to perform webrooming behavior (Kleinlercher et al., 2020; Santos \& Goncalves, 2019). In particular, consumers engage in webrooming for the purpose of information attainment and price comparison. The findings lend support to the qualitative work by Boardman and McCormick (2018) which indicated that webrooming can occur when consumers' feel sceptical about the product information found online. Interestingly, while Kang (2018) also revealed that while webroomers are motivated to gather product information, they are not, however interested in using webrooming as a means for price comparison. This is most likely explained by the fact that consumers who want to make the best price deal tend to stay online anyway as they have unmatchable price offerings (Aw, 2019).

As pioneers in the field, the aforementioned studies have shed some light to the literature of webrooming by providing empirical knowledge on the determinants of webrooming. Nevertheless, the findings from current literature are still far from providing a complete picture of the webrooming phenomenon, and more crucially important aspects of it still remain uncovered (Aw, 2019). For instance, Arora and Sahney (2018b) revealed the empirical relevance of perceived risk as a driver to webrooming, but remains unclear on the different forms of perceived risk that matter to webrooming. In addition, a systematic review conducted by Sahu et al. (2021) found that most of the related studies were based in the context of the United States. As demonstrated by their findings, out of the 92 research papers reviewed, more than half were based in the United States, far exceeding studies from other countries, such as India (8) and Malaysia (1). In terms of the methodology employed, a recent review study by Mishra et al. (2021) demonstrated that surveys $(41.95 \%)$ and modelling techniques $(18.88 \%)$ were the most frequently employed methods in the field of omnichannel retailing. Despite how little is known about webrooming, there is surprisingly scant exploratory research done in this research area. The finding is supported by Sahu et al. (2021) study, which revealed that only around $13 \%$ of research probed into omnichannel behavior used qualitative methods. Hence, adhering the suggestion by recent studies to undertake an inductive lens (Mishra et al., 2021), this study conducts a preliminary qualitative study to provide a more indepth understanding with regards to webrooming behavior. 


\section{METHODOLOGY}

The present study relied on qualitative method as it allows researchers to probe into richer nuances of responses, solving the limitations of prior webrooming literature that impose fixed categories of responses by using survey design. A series of in-depth interviews was conducted. In-depth interviews were selected as they are deemed to be more efficient, and are able to provide greater depth of information (Stokes \& Bergin, 2006). Prior to the interviews, participants were briefed for the scope of interview conversation and guaranteed anonymity in order to elicit honest responses, as well as minimize social desirability bias (Merriam \& Tisdell, 2016). The interest of frank opinions from participants was informed and stressed, in which there was no right or wrong answer. Consents for audio-recording were obtained from participants as well.

Data were obtained following a semi-structured interview guide. The nature of interviews tends to remain flexible and open-ended by allowing participants to have a certain extent of freedom in adding new ideas, which potentially enrich the content of research (Mason, 2006). The interview guide was designed revolving a few themes and respective possible prompts: (a) participants' last shopping experience using webrooming, (b) reasons for prior online information search (c) reasons for visiting physical stores for final purchase, and (d) experience with and perception towards webrooming. Each interview session lasted around thirty minutes on average.

A non-probability purposive and snowball sampling was employed to recruit participants who fall in the Millennials category (born between year 1982- 2004) (Hall et al., 2017). Additionally, participants must have webrooming experience in the past six months, for the sake of increasing probability of recall and minimize potential memory bias (Aw, 2020). Following the approach taken by Bandara et al. (2020), respondents were recruited through personal contacts and on a voluntary basis, and these respondents were asked to nominate other potential qualified respondents. Data saturation was reached after twelves interviews were conducted, whereby adequate information was gathered and no additional new information was identified (Guest et al., 2006). The sample size is deemed to be sufficient (Creswell, 1998; Kvale, 2007; MacCracken, 1992) and comparable to pertinent studies in cross-channel literature (Harris et al., 2018; Sit et al., 2018). The participants were aged between 19 to 28 . In terms of gender, $66.67 \%$ of them were females. Majority of the respondents $(50 \%)$ had completed a Bachelor's degree. In terms of monthly income, $66.67 \%$ of respondents earned below USD 500 and $33.33 \%$ earned between USD501 and USD 1000.

\section{RESULTS AND DISCUSSION}

\subsection{Data analysis}

At the initial stage of qualitative data analysis, interview transcripts were first imported into Quirkos software, a qualitative analysis software that offer highly visual and intuitive interface for data management and analysis. Subsequently, the gathered data was subjected to thematic analysis to identify themes pertinent to webrooming. Deductive thematic analysis was conducted specifically to answer the study's research question, which means that the data was coded based on knowledge of past research. This allows for the examination data, to see whether they support, align, include, or expand themes in previous research or theories in a similar context to as 
webrooming. Here, codes refer to most basic forms of attributes or elements of data which could be potentially meaningful to the researcher.

Using Quirkos software, relevant texts were dragged into a bubble "Quirks" where the assign of texts to codes were completed. For example, an interviewee commented that "I love to touch products when shopping. I feel more confident that way. For example, using the tester in physical stores allow me to cross check the information I got from online", was coded under "need for touch", one of the variables proposed by Flavián et al. (2016) and Santos and Goncalves (2019). Moving to next step, the researcher redirected the focus to identify themes at a broader level. This phase involves the assignment of varies codes into their respective themes where researcher groups the earlier created bubbles "Quirks". Themes are defined as concepts at a higher hierarchy which able to encompass recurring patterns in the data (Braun \& Clarke, 2009). Identified themes were interpreted in subsequent section and summarized. Finally, individual themes were reviewed until no additional new insights can be found.

\subsection{Findings}

\subsubsection{Consumer personal traits as motivators to webrooming behavior}

Consumer-related factors refer to factors associated with consumer individual differences, such as consumer traits that explains webrooming behavior. Consumer traits are related to consumers' predisposition to respond in a particular way (Mowen, 2000). Findings from in-depth qualitative interview suggested four potential consumer traits exhibited by webroomers.

Need for touch. Need for touch refers to consumers' preference for the extraction and utilization of information obtained through the haptic system (Peck \& Childers, 2003). Respondents express their need for physical inspection of products to ensure product quality and suitability. Additionally, they feel more confident with physical touching of products, which enable them to acquire additional complementary information. Consumers with high need for touch are less likely to rely on single online channel, and tend to combine different channel (with at least one as offline channel) to improve their purchase experience.

"I think that there are some differences which can be detected if I touch the purse physically... Physically touch is the safest way to ensure the quality and make a right purchase" (Participant 3, Female).

"I love to touch products when shopping. I feel more confident that way. For example, using the tester in physical stores allow me to cross check the information I got from online" (Participant 8 , Female).

Need for interaction. Need for interaction is defined as the degree to which consumers' have the tendency to emphasize personal contact during service encounters (Dabholkar, 1996). Various perceptions had been raised regarding respondents' need for personal interaction with in-store salespeople. Data suggested that majority of respondents perceive that assistance of in-store salespeople to be unnecessary and often times irritating. Nevertheless, there are still a few respondents who indicate their desire for interaction with salespeople during the shopping process to acquire additional information. 
"Most of the time, I like to shop by myself without being disturbed by salespeople... I do not want to interact too much with salespeople... Sometime I search information online first so I do not need to consult them" (Participant 4, Female).

"I like to interact with salespeople. I think I will get more product information from them" (Participant 6, Male).

Price comparison orientation. Price comparison-oriented consumers have a high need to compare price across different channels to search for better price deal (Heitz-Spahn, 2013). Respondents indicated their desire to purchase products at a fair price, driving the need to search and compare pricing information prior to purchase. On top of that, several interviewees believe that online search can lead to better chance of getting a fair price deal in physical stores.

"I want to compare prices and check whether or not there are discounts. I am a person who concerned with price. I do not want to buy a product with higher price" (Participant 9, Female).

"I think I can get a better price in physical stores after searching for information online" (Participant 6, Male).

Product knowledge. Product knowledge is the level of understanding of a good or service that might include having acquired information about its application, function, features, use and support requirements (Brucks, 1985). Lack of product knowledge has been indicated by respondents as an important reason they need to search online prior to offline purchase. In general, data suggested that inadequate product knowledge is associated with infrequent purchase and low familiarity. Few respondents explained that they still need to engage in information search even when equipped with prior knowledge, particularly for technological products that undergo frequent changes.

"I do not have enough knowledge in buying lipsticks. For example, what kind of lipsticks that are in the market, which one is good to use, what kind of colour looks good" (Participant 4, Female)

"I have certain level of knowledge with computers. But since technology keeps updating from time to time, I still need to search the latest info" (Participant 8, Male).

\subsubsection{Channel-related factors associated with webrooming behavior}

In the context of this study, channel-related factors refer to the consumers' perception towards the specific channel attributes of online channel. In particular, in the context of webrooming, channelrelated factors mainly concern about the advantages of search online and purchase offline. The study identifies five main channel-related factors associated with webrooming behavior.

Online search convenience. Online search convenience is associated with the perceived ease and speed which consumers can obtain product information online (Verhoef et al., 2007). When respondents were asked why they select online channel in the search phase of shopping, they concurred with the search convenience offered by online channel. Respondents believe that information can be gathered easier and faster from online channels. 
"Searching information on the Internet is easy and fast. I can search information from almost anywhere" (Participant 4, Female)

Perceived usefulness of online reviews. Perceived usefulness of online review is defined as the extent to which consumers believe that online reviews would aid their decision-making in shopping process (Park \& Lee, 2009). Several interviewees declared that online reviews help them to fortify purchase judgment because the reviews are deemed to be more objective compared to commercial advertisement. Conversely, a few respondents questioned the usefulness of online reviews, claiming that online reviews can be fake and manipulated.

"Online review is useful as it helps me to judge and evaluate the product. Reading reviews helps me avoid being misled by the advertisement...I think the information from online might be better than information from the physical stores because I can get opinions from other users and their opinions are more objective than advertisement" (Participant 4, Female)

"Personally, I do not trust online reviews and I don't think they are useful. For me, the reviews are not $100 \%$ true because the reviews can be manipulated by certain parties" (Participant 2, Male)

Immediate possession. Immediate possession is recognized as an advantage of webrooming behavior (Wang et al., 2016). It concerns with the channel ability to enable quick product possession after payment has been made. One of the main reasons respondents make their final purchase in physical stores is to acquire the product immediately, implying that immediate ownership of the product is valued in return for money paid. Therefore, physical stores appear to be the best option for immediate possession with their inherited characteristic of concurrent physical presence.

"Yes, I prefer to get my laptop immediately. I feel like once my is money out, I should be able to use the product right away...I can only get my laptop immediately from physical stores, as online delivery is slow" (Participant 8 , Male)

Perceived helpfulness of in-store salespeople. Perceived helpfulness of salespeople determines the performance of in-store service (Rapp et al., 2015). A few respondents perceive in-store salespeople to be helpful in providing information compared to online channel. On the contrary, the data showed contradicting evidences that in-stores salespeople are not helpful yet considered as a negative attribute of physical stores.

"I choose physical stores to make purchases because there are staffs available to explain the functions and features of the smartphone to me. Compared to online information, I prefer information given by salespeople in the physical store" (Participant 2, Male).

"I think they do not have experience in using the product. Also, they keep promoting the products that they want to sell. They are not sincere in helping. They would not help me to make comparison between one product with another. Even they know the product, they will not tell the truth. I do not like to consult them for product information" (Participant 3, Female).

Perceived risk. Perceived risk plays a vital role in determining consumers' shopping channel preferences (Herhausen et al., 2015). Generally, perceived risk is known as the uncertainty and 
anticipation of losses involved in purchase (Featherman \& Pavlou, 2003; Peter \& Ryan, 1976). Consumers become worried when they sense the uncertainty in attaining their goal of purchase (Forsythe \& Shi, 2003). Respondents indicated that perceived risk associated with online channel compels them to switch to physical stores for final purchase. Three types of risk were identified, namely product risk (consumers' experience of losses with regards to their product due to the unmet expectation), financial risk (probability of monetary loss associated with purchasing a product) and delivery risk (the uncertainty consumers face during the delivery process of their purchased products, such as delay in delivery, goods damaged in delivery as well as wrong delivery).

"If I purchase online, online vendors may give me products which have flaws and defects, either purposely or not." (Participant 3, Female).

"Delivery is another concern of me to purchase online. If I really want to buy any expensive product, I would make my purchase at physical shops. I do not have confidence with the shipping process. I afraid the items would go missing" (Participant 2, Male).

"I worry about the payment, whether they can be properly executed...maybe there are some hidden charges" (Participant 6, Female).

\subsubsection{Consumer experience associated with webrooming behavior}

Consumer experience is the holistic perception of their experience with an organization's business or a brand. It is the result of every touch-point interaction a customer has with a business, navigating from the website, to talking to customer service, up to the purchase of products and/or services. Consumer experience will impact on customers' perception of a business, their satisfaction levels and the decision whether or not to come back. The study identifies consumer experience, as manifested in smart shopping perception in relation to webrooming.

Smart shopping perception. Several benefits of webrooming were identified. Respondents perceive webrooming in a positive way, in which they think that they have saved money, time, and effort, as well as made correct purchase decision through their webrooming experience. Combined together, the results correspond to the smart shopping perception pioneered by Atkins and Kim (2012), which refers to perception of being smart due to minimum expenditure of time, money, or energy as well as perception of making the right purchase.

"I can buy products at a considerably reasonable price in physical stores...I do not need to spend too much time searching information in the physical stores as I already have clear thought of what type of dress I want. I think overall webrooming helps to improve shopping efficiency" (Participant 4 , Female)

"I feel happy after my last my webrooming experience. I saved my money and time", (Participant 7, Male)

"I think webrooming is a smart shopping method. I really save a lot of time in looking for the product and I think I have made a correct choice of my purse" (Participant 3, Female) 


\subsubsection{Product category as a situational condition to webrooming}

Product category has long been acknowledged as one of the most pronounces form of situational factors in the context of retail shopping (Gehrt \& Yan, 2004). Consumers tend to exhibit varying shopping behaviours that depend upon the purchase situation of different types of products. Search/experience classification has been established as an important product categorization paradigm in the marketing literature (Weathers et al., 2007). The paradigm distinguishes search and experience dominant products depend on the degree to which consumers can evaluate the attributes of goods before their purchase (Klein, 1998; Weathers et al., 2007). A product with attributes which can be searched in an economically feasible way is termed search products, while experience products are those for which the research is not economically feasible (Frasquet, Mollá, $\&$ Ruiz, 2015). Electronics and apparels are the examples of search and experience products, respectively (Lian \& Yen, 2013; Frasquet et al., 2015). Interviewees indicate their webrooming experience for a particular product type which is difficult to evaluate online.

"I buy at physical stores because I want to feel the materials. Especially when buying skincare, I need to put the product on my skin to see whether it absorbs or not, or whether or not it feels good. If I buy online, I would not know about that" (Participant 1, Female)

"The touching is important when buying skincare product" (Participant 6, Female)

"The risk depends on the product I buy" (Participant 7, Male)

"I do not really rely on reviews when buying clothes, but I will look for them when buying electronic products" (Participant 11, Male)

\subsection{Discussion}

Cross-channel shopping is an area of growing interest in research given its practical relevance to the performance of retailers of all kinds in the current retail environment. To this end, the objective of this study is to inquire into the drivers, experience as well as the situational conditions under young consumers' webrooming behavior. The qualitative findings identified four major themes in explaining the adoption of webrooming behavior, namely motivations, (individual-traits and channel-related attributes), smart shopping perception and product category.

For consumers' individual traits as a motivator for webrooming, the findings indicate need for touch as a primary motive for consumers to engage in this behavior, supporting Flavián et al. (2016) notion that need for touch is imperative in the context of webrooming. Although there have been vast improvements in online channels, especially in terms of providing an immersive experience through 3-D technology, its inherent characteristics is still far behind consumers' expectations of sensory experience. Such deficiency compels consumers to webroom as physical stores are able provide direct physical experience with products, and thus, the feeling of reassurance.

Next, the results show that consumers' webrooming behavior is determined by the need for interaction with salespeople. This theme is rather interesting and yet to be uncovered in existing webrooming literature. Contradicting evidences from the study suggest that there are consumers who exhibit high and low need for interaction involve in webrooming, and for different reasons. 
Consumers who exhibit high need for interaction are drawn by the perceived helpfulness of instore salespeople, believing that human interaction and assistance is vital to making an optimal purchase, suggesting human service still play an important service even in currently technologyenabled retailing landscape (Vannucci \& Pantano, 2019). Conversely, consumers with low need for interaction tend to search for information online prior to their visit to physical stores because they prefer to limit their time interacting and consulting with salespeople. To a certain extent, webrooming provides them the mechanism to avoid prolonged interactions with salespeople.

On top of that, this study reveals that consumers adopt webrooming with the aim of comparing and getting a better price deal. This result substantiates previous findings in the literature (Heitz-Spahn, 2013; Kim et al., 2019). Online channels are generally deemed as the most accessible channel for product information comparison, which at the very basic includes price details (Verhoef et al., 2007). Consumers do not only search for price information of products selling online, but also for products selling in physical stores. According to Aw (2019), a prior information search online provides consumers a contextual reference prices for a particular product, which subsequently facilitate purchase decision in physical stores. Hence, it has been shown that using both online and offline channels are more beneficial for price comparison compared to using single channel (Kim et al., 2019).

Another important and novel finding is the role of product knowledge as motivation of webrooming, lending support to Lin and Chen (2006) notion that the amount of product knowledge possessed by consumers, influence their information search behavior as well as purchase decision. This finding is yet to be tested in prior webrooming literature. Webrooming has been described as a shopping behavior that are highly involved, in which consumers devote prolonged time and effort to search and examine products before buying (Flavián et al., 2016; Viejo-Fernández et al., 2018), partly due to consumers' lack of product knowledge. The finding is consistent with the uncertainty reduction theory, which postulate that a greater extent of information processing (search products online and examine products offline) is carried out when consumers face uncertainty (i.e. inadequate product knowledge) while looking for correctness in decision making (Tormala et al., 2008).

The second theme uncovered by the study, is the effect of channel-related factors as a motivator for consumers to webroom, particularly in the initial online search phase and subsequent phase of offline purchase. In terms of why consumers selected online channels during initial search phase, two key online channel-related factors have been articulated, namely online search convenience and perceived usefulness of online reviews. This is in good agreement with the findings of Arora and Sahney (2019). Online searching is intuitively convenient, particularly for young consumers who are generally digital natives. More importantly, this study uncovers the importance of online reviews as a relevant channel-related factor driving webrooming, indicating reading "opinions of others" as a norm of pre-purchase preparation. This concurs well with Flavián et al. (2016) study that found online reviews to positively influence offline purchase decision in the process of webrooming.

Furthermore, the data identifies online perceived risk as explanation of consumers' final act of purchase in physical stores, corroborating to prior literature (Arora \& Sahney 2019; Santos \& Goncalves, 2019). Three main facets of risk revealed are product risk, financial risk, and delivery risk. Such findings imply that online purchase risk may have been reduced following the 
advancement of technology and online retail policies, but they do still matter at the current moment, even for digital natives. Findings in the present study further shows that some consumers make their final purchase in physical stores for immediate possession and perceived helpfulness of instore salespeople. The immediate possession attribute of physical stores motivates webrooming, in line with that of Gensler et al. (2017), suggesting that channels with the fastest delivery is advantageous in capturing final act of purchase. It is believed that the effect is pronounced even more for Millennials, which are often driven by the need for instant gratification (Eastman et al., 2018). Similarly, Arora and Sahney (2019) identified salespeople assistance as an offline purchase benefit that drives webrooming behavior. Salespeople can still be an asset for offline retailers under the premise that they carry positive attributes, such as sincerity, trustworthiness, and knowledgeable as well as being adaptive. Hence, in-store salespeople's traditional role as the controller of consumer shopping behavior is hardly relevant in current omnichannel retail environment, especially seeing that webroomers have been described as "smart shoppers" who are well-prepared before entering physical stores and not easily influenced (Viejo-Fernández et al., 2018).

In terms of experience and perception towards webrooming, the results of present study indicate that webrooming is perceived as a useful cross-channel shopping method that provides the best consumer experience for Millennial consumers. The three components of benefits, namely right purchase, time saving, and monetary saving derived from webrooming seems to corroborate with the concept of smart shopping perception (Atkins \& Kim 2012; Flavián et al., 2019, Flavián et al., 2020), suggesting webrooming as an effective mean to fulfill common shopping goals of uncertainty reduction and savings. Taken together, these findings are able to explain why webrooming is the most prevalent form of cross-channel shopping behavior (Flavián et al., 2016).

Finally, the findings of the study provided key evidence on the importance of product category in webrooming context, providing support to idea of Heitz-Spahn (2013). Heitz-Spahn (2013) indicated that product category can lead to different consumer behaviors, and the author urged future studies to test the moderating effect on cross-channel shopping behavior. Similar concern has been raised in the webrooming literature as well (Arora \& Sahney 2019; Santos \& Goncalves, 2019). For instance, Santos and Goncalves (2019) proposed that different drivers of webrooming could exist when purchasing search and experience products. As outlined by Aw (2020) who took a complexity view on consumers' shopping behavior, purchasing products of different kinds gives rise to emphasis on certain motivation and channel attributes.

\section{CONCLUSION}

Delivering positive shopping experiences has been a mantra for retailers. The findings from this study suggests that retailers of all kinds, either pure play online, offline, or multichannel should emphasize on utilizing associated channel attributes in dealing with webrooming behavior. For pure play online and multichannel retailers who wish to close sales online, leveraging on the strength of online channel, including information richness and ease of gathering information could be the key to combat webrooming. Consumers' pre-purchase phase tends to take place online, providing an advantage to pure play online retailers. However, pure play online retailers need to formulate effective strategies to create channel lock-in as the means to close sales online. For instance, they should refine their marketing communication practices by stimulating more useful 
experience-based reviews, which could potentially transform experience products into search products, and eventually alleviate consumers' need to touch and consult in-store salespeople (Park \& Lee, 2009). In addition, it is paramount for pure play online retailers to resolve consumers' need for touch. In such instance, the employment of cutting edge visual- and haptic-enabling technologies, such as 3D virtual tours should be considered in order to create a seamless retail experience (Papagiannidis et al., 2013).

The implications can be further extended to offline and multichannel retailers, providing them some guidance to foster and handling webrooming behavior. The primary needs of webroomers, namely need for interaction, need for obtaining additional information and better price deal require adequate fulfillment and greater attention from offline and multichannel retailers. Retailers should enable the physical inspection of products and ensure the availability of in-store salespeople for additional assistance. Although it is apparently hard for offline retailers to outperform in terms of pricing, appropriately tailored monetary promotion, such as in-store only redeemable coupons still should be done to minimize the discrepancy. On top of that, offline and multichannel retailers should move towards the concept of smart-retailing by integrating in-store technologies to foster a conducive information search environment (Dennis et al., 2017). For instance, it has been shown that a prudently integrated online reviews in physical stores help to induce webrooming behavior (Li et al., 2019). In addition, retailers with physical stores should realize and utilize the inherent strength of offline channel identified in this study, immediate possession and salespeople. They should stimulate consumers' instant gratification through their marketing communication practices as well as improve the quality of their in-store salespeople. As outlined in the findings, in-store salespeople are often unwelcomed for their perceived disturbance, which perhaps is a result of close monitoring distance with consumers and pressure selling. As such, adaptive selling strategies should be acquired and deployed by in-store salespeople. It is also worthwhile to note the importance of product category in webrooming context, echoing the findings from Santos and Goncalves (2019) that different drivers of webrooming could exist when purchasing search and experience products. The uncertainty of product purchase is highly dependent on its experience attributes, the need for touch is augmented when consumers are involving in the purchase of fashion and cosmetic products. Online retailers within these product categories should provide very specific information (i.e., highly descriptive materials etc.) to increase the experience value for consumers.

There are several limitations to the study. Although the present study provides a theoretical ground to understand determinant of Millennials' webrooming behavior, it lacks empirical rigor to quantify the relationships between the proposed constructs. Secondly, previous studies have asserted that emotion can be decisive in consumer decision making process and thus very much relevant to retailing and consumer services (Lajante \& Ladhari 2019). Future studies can take the lens of consumers' experience during the process of webrooming, such as consumers' emotions. It would be fruitful to understand the emotional, social, and physical interactional process occur through the cross-channel shopping journey, especially through the lens of non-linear asymmetrical approach (Chuah et al., 2021). Thirdly, the present study considered only the perspective of consumers, but not stakeholders such as the in-store salespeople, as they are also equally affected by webrooming. This is particularly important as it resonates with how in-store salespeople need to adapt their selling approach for webroomers who are described as smart and empowered shoppers (Flavián et al., 2019). Finally, this study focuses on Millennials sample, therefore future studies can extend findings by exploring similarities and differences between 
Millennials and other consumer groups, particularly the Generation Z, a fast-growing segment in the area of consumer online shopping.

\section{ACKNOWLEDGEMENT}

We would like to thank Geran Putra Malaysia, Universiti Putra Malaysia for funding our research. Grant number: 9677800.

\section{REFERENCES}

Arora, S., \& Sahney, S. (2018a). Antecedents to consumers' showrooming behaviour: an integrated TAM-TPB framework. Journal of Consumer Marketing, 35(4), 438-450.

Arora, S., \& Sahney, S. (2018b). Consumer's webrooming conduct: an explanation using the theory of planned behavior. Asia Pacific Journal of Marketing and Logistics, 30(4), 10401063.

Arora, S., \& Sahney, S. (2019). Examining consumers' webrooming behavior: an integrated approach. Marketing Intelligence \& Planning, 37(3), 339-354.

Atkins, K. G., \& Kim, Y. K. (2012). Smart shopping: Conceptualization and measurement. International Journal of Retail \& Distribution Management, 40(5), 360-375.

Aw, E. C.-X. (2019). Understanding the webrooming phenomenon. International Journal of Retail \& Distribution Management, 47(10), 1074-1092.

Aw, E. C.-X. (2019). Understanding consumers' paths to webrooming: A complexity approach. Journal of Retailing and Consumer Services, 53, 101991.

Aw, E. C.-X., Basha, N. K., Ng, S. I., \& Ho, J. A. (2021). Searching online and buying offline: Understanding the role of channel-, consumer-, and product-related factors in determining webrooming intention. Journal of Retailing and Consumer Services, 58, 102328.

Bandara, R., Fernando, M., \& Akter, S. (2020). Explicating the privacy paradox: A qualitative inquiry of online shopping consumers. Journal of Retailing and Consumer Services, 52, 101947.

Boardman, R., \& McCormick, H. (2018). Shopping channel preference and usage motivations. Journal of Fashion Marketing and Management: An International Journal, 22(2), 270-284.

Braun, V., \& Clarke, V. (2006). Using thematic analysis in psychology. Qualitative Research in Psychology, 3(2), 77-101.

Brucks, M. (1985). The effects of product class knowledge on information search behavior. Journal of Consumer Research, 12(1), 1-16.

Chuah, S. H. W., Aw, E. C. X., \& Yee, D. (2021). Unveiling the complexity of consumers' intention to use service robots: An fsQCA approach. Computers in Human Behavior, 123, 106870.

Creswell, J. W. (1998). Qualitative Enquiry and Research Design: Choosing Among Five Traditions. Sage, Thousands Oak.

Dabholkar, P. A. (1996). Consumer evaluations of new technology-based self-service options: an investigation of alternative models of service quality. International Journal of Research in Marketing, 13(1), 29-51. 
Daunt, K. L., \& Harris, L. C. (2017). Consumer showrooming: Value co-destruction. Journal of Retailing and Consumer Services, 38, 166-176.

Dennis, C., Bourlakis, M., Alamanos, E., Papagiannidis, S., \& Brakus, J. J. (2017). Value cocreation through multiple shopping channels: The interconnections with social exclusion and well-being. International Journal of Electronic Commerce, 21(4), 517-547.

Eastman, J. K., Iyer, R., Shepherd, C. D., Heugel, A., \& Faulk, D. (2018). Do they shop to stand out or fit in? The luxury fashion purchase intentions of young adults. Psychology \& Marketing, 35(3), 220-236.

Featherman, M. S., \& Pavlou, P. A. (2003). Predicting e-services adoption: a perceived risk facets perspective. International Journal of Human-Computer Studies, 59(4), 451-474.

Flavián, C., Gurrea, R., \& Orús, C. (2016). Choice confidence in the webrooming purchase process: The impact of online positive reviews and the motivation to touch. Journal of Consumer Behaviour, 15(5), 459-476.

Flavián, C., Gurrea, R., \& Orús, C. (2019). Feeling Confident and Smart with Webrooming: Understanding the Consumer's Path to Satisfaction. Journal of Interactive Marketing, 47, $1-15$.

Flavián, C., Gurrea, R., \& Orús, C. (2020). Combining channels to make smart purchases: The role of webrooming and showrooming. Journal of Retailing and Consumer Services, 52, 101923.

Forsythe, S. M., \& Shi, B. (2003). Consumer patronage and risk perceptions in Internet shopping. Journal of Business research, 56(11), 867-875.

Frasquet, M., Mollá, A., \& Ruiz, E. (2015). Identifying patterns in channel usage across the search, purchase and post-sales stages of shopping. Electronic Commerce Research and Applications, 14(6), 654-665.

Gehrt, K. C., \& Yan, R. N. (2004). Situational, consumer, and retailer factors affecting Internet, catalog, and store shopping. International Journal of Retail \& Distribution Management, 32(1), 5-18.

Gensler, S., Neslin, S. A., \& Verhoef, P. C. (2017). The showrooming phenomenon: It'smore than just about price. Journal of Interactive Marketing, 38, 29-43.

Guest, G., Bunce, A., \& Johnson, L. (2006). How many interviews are enough? An experiment with data saturation and variability. Field methods, 18(1), 59-82.

Hall, A., Towers, N., \& Shaw, D. R. (2017). Understanding how Millennial shoppers decide what to buy. International Journal of Retail \& Distribution Management, 45(5), 498-571.

Haridasan, A. C., \& Fernando, A. G. (2018). Online or in-store: unravelling consumer's channel choice motives. Journal of Research in Interactive Marketing, 12(2), 215-230.

Harris, P., Riley, F. D. O., \& Hand, C. (2018). Understanding multichannel shopper journey configuration: An application of goal theory. Journal of Retailing and Consumer Services, 44, 108-117.

Heitz-Spahn, S. (2013). Cross-channel free-riding consumer behavior in a multichannel environment: An investigation of shopping motives, sociodemographics and product categories. Journal of Retailing and Consumer Services, 20(6), 570-578.

Herhausen, D., Binder, J., Schoegel, M., \& Herrmann, A. (2015). Integrating bricks with clicks: retailer-level and channel-level outcomes of online-offline channel integration. Journal of Retailing, 91(2), 309-325.

Jain, S., \& Shankar, A. (2021). Exploring gen Y luxury consumers' webrooming behavior: an integrated approach. Australasian Marketing Journal, 1-10. https://doi.org/10.1177/18393349211022046 
Kalyanam, K., \& Tsay, A. A. (2013). Free riding and conflict in hybrid shopping environments: Implications for retailers, manufacturers, and regulators. The Antitrust Bulletin, 58(1), 1968.

Kang, J. Y. M. (2018). Showrooming, webrooming, and user-generated content creation in the omnichannel era. Journal of Internet Commerce, 17(2), 145-169.

Kim, E., Libaque-Saenz, C. F., \& Park, M. C. (2019). Understanding shopping routes of offline purchasers: selection of search-channels (online vs. offline) and search-platforms (mobile vs. PC) based on product types. Service Business, 13(2), 305-338.

Klein, L. R. (1998). Evaluating the potential of interactive media through a new lens: Search versus experience goods. Journal of Business Research, 41(3), 195-203.

Kleinlercher, K., Linzmajer, M., Verhoef, P. C., \& Rudolph, T. (2020). Antecedents of webrooming in omnichannel retailing. Frontiers in Psychology, 11, 3342.

Koetsier, J. (2018). The new retail: Showrooming, webrooming, and scanswapping are how Millennials shop. https://www.inc.com/john-koetsier/showrooming-webroomingscanswapping-are-new-retail.html

Kvale, S. (2007). Doing Interviews. Sage Publications, Los Angeles.

Lajante, M., \& Ladhari, R. (2019). The promise and perils of the peripheral psychophysiology of emotion in retailing and consumer services. Journal of Retailing and Consumer Services, 50, 305-313.

Lee, S. H., \& Jung, S. (2019). Fashion consumers' channel-hopping profiles by psychographics and demographics. International Journal of Market Research, 62(5), 615-632.

Li, Y., Li, G., Tayi, G. K., \& Cheng, T. C. E. (2019). Omni-channel retailing: Do offline retailers benefit from online reviews?. International Journal of Production Economics, 218, 4361.

Lian, J. W., \& Yen, D. C. (2013). To buy or not to buy experience goods online: Perspective of innovation adoption barriers. Computers in Human Behavior, 29(3), 665-672.

Lin, L. Y., \& Chen, C. S. (2006). The influence of the country-of-origin image, product knowledge and product involvement on consumer purchase decisions: an empirical study of insurance and catering services in Taiwan. Journal of Consumer Marketing, 23(5), 248265.

Luthi, B. (2014). Engaging Millennials online. https://chainstoreage.com/news/engagingmillennials-online

MacCracken, G. D. (1992). The Long Interview ( $7^{\text {th }}$ ed). Newbury Park, CA: Sage Publications.

Manss, R., Kurze, K., \& Bornschein, R. (2020). What drives competitive webrooming? The roles of channel and retailer aspects. The International Review of Retail, Distribution and Consumer Research, 30(3), 233-265.

Mason, J. (2006). Mixing methods in a qualitatively driven way. Qualitative Research, 6(1), 9-25.

McCarthy, A. (2017). Millennial holiday shoppers did their research online before buying in-store. https://www.emarketer.com/Article/Millennial-Holiday-Shoppers-Their-Research-OnlineBefore-Buying-In-Store/1015009

Merriam, S. B., \& Tisdell, E. J. (2016). Qualitative research: A guide to design and implementation $\left(4^{\text {th }} \mathrm{ed}\right)$. San Francisco, CA: John Wiley \& Sons.

Mishra, R., Singh, R. K., \& Koles, B. (2021). Consumer decision-making in Omnichannel retailing: Literature review and future research agenda. International Journal of Consumer Studies, 45(2), 147-174. 
Mosquera, A., Juaneda Ayensa, E., Pascual, C. O., \& Murillo, Y. S. (2019). Omnichannel Shopper Segmentation in the Fashion Industry. Journal of Promotion Management, 25(5), 681699.

Mowen, J. C. (2000). The 3M model of motivation and personality: Theory and empirical application to consumer behavior. Boston: Kluwer Academic.

Papagiannidis, S., Bourlakis, M., Alamanos, E., \& Dennis, C. (2017). Preferences of smart shopping channels and their impact on perceived wellbeing and social inclusion. Computers in Human Behavior, 77, 396-405.

Papagiannidis, S., Pantano, E., See-To, E. W., \& Bourlakis, M. (2013). Modelling the determinants of a simulated experience in a virtual retail store and users' product purchasing intentions. Journal of Marketing Management, 29(13-14), 1462-1492.

Park, C., \& Lee, T. M. (2009). Antecedents of online reviews' usage and purchase influence: An empirical comparison of US and Korean consumers. Journal of Interactive Marketing, 23(4), 332-340.

Peck, J., \& Childers, T. L. (2003). To have and to hold: The influence of haptic information on product judgments. Journal of Marketing, 67(2), 35-48.

Peter, J. P., \& Ryan, M. J. (1976). An investigation of perceived risk at the brand level. Journal of Marketing Research, 13(2), 184-188.

PricewaterhouseCoopers. (2015). Total retail 2015: Retailers and the age of disruption. https://www.pwc.com/id/en/publications/assets/cips/total-retail-february-2015.pdf

Rapp, A., Baker, T. L., Bachrach, D. G., Ogilvie, J., \& Beitelspacher, L. S. (2015). Perceived customer showrooming behavior and the effect on retail salesperson self-efficacy and performance. Journal of Retailing, 91(2), 358-369.

Sahu, K. C., Naved Khan, M., \& Gupta, K. D. (2021). Determinants of webrooming and showrooming behavior: A systematic literature review. Journal of Internet Commerce, 20(2), 137-166.

Santos, S., \& Gonçalves, H. M. (2019). Multichannel consumer behaviors in the mobile environment: Using fsQCA and discriminant analysis to understand webrooming motivations. Journal of Business Research, 101, 757-766.

Sit, J. K., Hoang, A., \& Inversini, A. (2018). Showrooming and retail opportunities: A qualitative investigation via a consumer-experience lens. Journal of Retailing and Consumer Services, 40, 163-174.

Stokes, D., \& Bergin, R. (2006). Methodology or "methodolatry"? An evaluation of focus groups and depth interviews. Qualitative market research: An international Journal, 9(1), 26-37.

Tormala, Z. L., Rucker, D. D., \& Seger, C. R. (2008). When increased confidence yields increased thought: A confidence-matching hypothesis. Journal of Experimental Social Psychology, 44(1), 141-147.

Van Baal, S., \& Dach, C. (2005). Free riding and customer retention across retailers' channels. Journal of Interactive Marketing, 19(2), 75-85.

Vannucci, V., \& Pantano, E. (2019). Digital or human touchpoints? Insights from consumer-facing in-store services. Information Technology \& People, 33(1), 296-310.

Verhoef, P. C., Kannan, P. K., \& Inman, J. J. (2015). From multi-channel retailing to omni-channel retailing: Introduction to the special issue on multi-channel retailing. Journal of Retailing, 91(2), 174-181.

Verhoef, P. C., Neslin, S. A., \& Vroomen, B. (2007). Multichannel customer management: Understanding the research-shopper phenomenon. International Journal of Research in Marketing, 24(2), 129-148. 
Viejo-Fernández, N., Pérez, M. J. S., \& Vázquez-Casielles, R. (2018). Webroomers versus showroomers: Are they the same? Journal of Business Research, 92, 300-320.

Viejo-Fernández, N., Sanzo-Pérez, M. J., \& Vázquez-Casielles, R. (2019). Different kinds of research shoppers, different cognitive-affective consequences. Spanish Journal of Marketing-ESIC, 23(1), 45-68.

Wang, Y. M., Lin, H. H., Tai, W. C., \& Fan, Y. L. (2016). Understanding multi-channel research shoppers: an analysis of Internet and physical channels. Information Systems and eBusiness Management, 14(2), 389-413.

Weathers, D., Sharma, S., \& Wood, S. L. (2007). Effects of online communication practices on consumer perceptions of performance uncertainty for search and experience goods. Journal of Retailing, 83(4), 393-401.

Wolny, J., \& Charoensuksai, N. (2016). Multichannel customer journeys: Mapping the effects of Zmot, showrooming and webrooming. Journal of Direct, Data and Digital Marketing Practice, 15(4), 317-326.

Zollo, L., Filieri, R., Rialti, R., \& Yoon, S. (2020). Unpacking the relationship between social media marketing and brand equity: The mediating role of consumers' benefits and experience. Journal of Business Research, 117, 256-267. 


\section{APPENDIX}

\section{Focused questions}

1)Why do you choose to search online prior to making purchase in physical stores?

2)Why do you choose not to make purchase online? What do you think about online shopping?

3) Why you choose to make purchase in physical stores

4) How do you think webrooming can help you in your shopping process?

5) What do you expect to gain through webrooming?

6) Have your expectations been met? Can you explain more about it?

7) How do you feel during the process of webrooming?

\section{Quirkos canvas view}

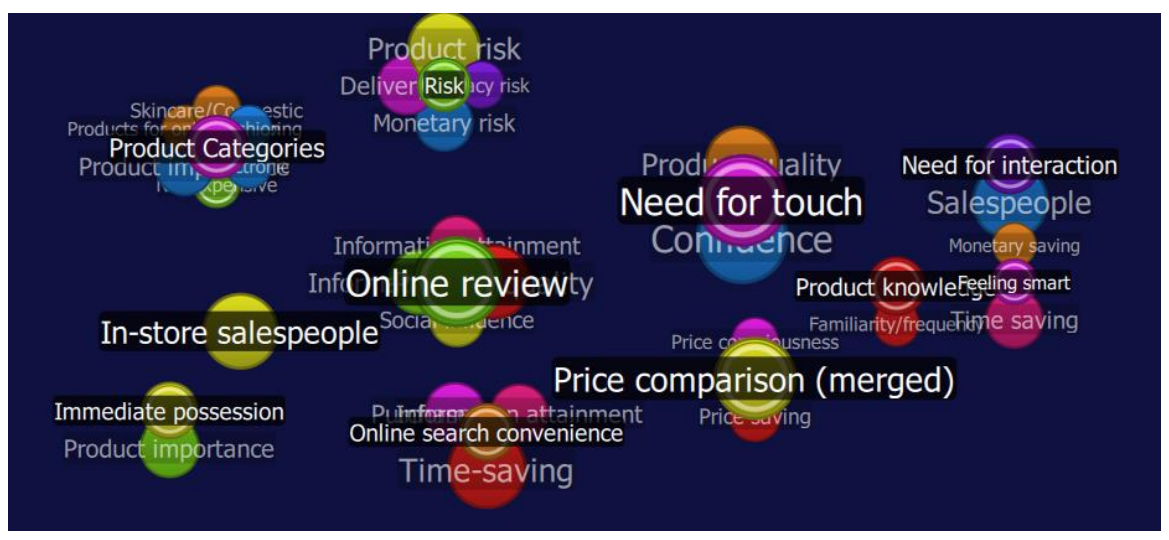

